\title{
Danish biobank legislation, a simple approach?
}

\author{
Kirsten Ohm Kyvik \\ Institute of Regional Health Services Research (IRS), University of Southern Denmark, and \\ Odense Patient Data Explorative Network (OPEN), Odense University Hospital \\ Correspondence: Kirsten Ohm Kyvik, Institute of Regional Health Services Research (IRS), University of Southern Denmark, \\ J.B. Winsløwsvej 19, DK-5000 Odense C, Denmark \\ E-mail:kkyvik@health.sdu.dk
}

In the mid 1990's it had become obvious in Denmark as elsewhere, that the technical and scientific development in biomedical and health science had resulted in a growing number of biobanks and other collections of information, e.g. research registries and electronic patient information in hospitals. A biobank working group was therefore established by the Ministry of Interior and Health with the specific aim to scrutinize the Danish laws and recommend whether a new biobank law would be needed in order to ensure confidentiality and safety of the biological material and the citizens who donated these (1).

The result of the working group was that the Danish legislation was well suited to cover also biobanks, since confidentiality and safety would be secured if biobanks were considered as other collections of data, e.g. registries. Today, biobanks are covered by the same Acts and institutions as other biomedical and health research, i.e. The Act on Processing of Personal Data, The Act on Scientific Ethical Committees, The Act on Scientific Ethical Handling of Health Sciences Research and The Health Act (2-5) and the Data Protection Agency and the Committees on Biomedical Research Ethics. A specific act on biobanks was thus not passed in Denmark.

A biobank in Denmark is defined as a structured collection of human biological material, which is accessible for research according to certain criteria. Typically, the biospecimens and other health information contained in the biobanks can be linked to individual persons, either as anonymised or identifiable data. Storage has to be longer than the time period required to collect and analyze the samples in order for the collection to be a biobank. This means that Danish biobanks are covered by the Act on Processing of Personal Data (2) because biobanks can be seen as a manual "filing system". All collections of human data, be they manual or electronic, have to be notified to and approved by the Danish Data Protection Agency before registration, transmission or other forms of data processing can take place. A researcher can apply for approval for this as a private project, which is done directly to the Agency. Research taking place in hospitals is notified to the Agency through the hospital owner, The Danish Regions, since 2010.

Processing of biological material, not forming a biobank, as part of a "private" project, i.e. the collector is not an institution, is also subject to notification and authorization, while processing in public institutions, e.g. hospitals, are not. Examples of private use could be collecting and analyzing biological material as part of a project and then destroying the rest of the samples. The so-called private collector will usually be a scientist who has chosen to apply to the Data Protection Agency as a private person instead of letting the institution take care of this. Processing in public institutions could be, for example, analyzing blood samples for diagnostic purposes.

Because of the sensitive nature of biological material, the Data Protection Board requires special guidelines for storage and usage of biobanks. Furthermore the Agency requires a specific purpose, which is usually more informal than a scientific aim or hypothesis. Examples of such purposes could be: To collect a biobank of sperm to provide for insemination of infertile women, or to establish a biobank in order to identify genes or markers for complex diseases.

When a project is finished or biological material is not to be used more, the biological material has to be either destroyed or anonymised, and anonymised material can be stored without authorization from the Data Protection Agency. Obviously, biological material which cannot be linked back to for example clinical data is less valuable for scientific purposes.

Biological material in biobanks, anonymised or person identifiable, can be used for other projects or transferred to other researchers, but this requires special permission. This permission is not required when a laboratory conducts the technical analysis within the scope of the original research project because in this situation the laboratory is seen as a handling the data in the same way as, for example, a statistician. Nonetheless, such an agreement about technical assistance requires that the Data Protection Agency is notified.

Biomedical Ethical Committees do not have the authority to approve the creation of biobanks, which is done by the Data Protection Agency $(3,4)$. This means that the sole collection of a biobank without a specific scientific aim or hypothesis is not subject to application to the biomedical ethics committees. An example could be to collect blood samples from a number of persons in order to establish a biobank for pharmacogenetic research. When the samples are to be used in order to test a hypothesis or search for genes for a specific phenotype, then each specific project has to be approved by the ethical committees. In practice most 
researchers describe the creation of biobanks in the application to the ethical committees, nonetheless. Most projects apply for usage of biological material in close proximity with the creation of the biobank, e.g. as part of a Ph.D. project. In this case the informed consent form includes both the project as such and the specific purpose for the analysis of the material and all formalities are covered. Researchers should be aware of the fact, though, that they cannot ask for consent in the form of a "blank cheque" for all future uses. If researchers want to do new analysis, for example, 5 years later, or if they want to analyze biological markers not specified in the original application, they need to reconsent the donors of the biological material. It is possible for the ethics committees to give exemptions from this requirement if a considerable number of donors are unavailable, e.g. if they are dead.

The Danish system can in some cases cause problems for researchers if they are not aware of these caveats. Let us consider a research project in a clinical department or out-patient clinic of patients with for example allergic diseases. As part of this project a biobank has been created with consent from the Data Protection Agency. The patients have been asked for consent to take part in the scientific project and have blood samples taken, but as the biobank was not part of the original project approved by the ethical committee, the patients were only asked to give oral consent during the sampling. This is not contrary to the Danish Health Act, which stipulates that patients should provide informed consent to all forms of treatment, either in writing, orally or implicit, depending on the circumstances. If this biobank is to be used later, these patients have to provide written informed consent at that time before the samples can be used, as this is required by the ethics committees.

In conclusion, in Denmark there is no specific act on biobanks, the creation and usage of which are covered by existing legislation on data protection and scientific ethical committees. For the most part, this works very well and is probably less confusing than having another law. However, understanding the distinction between when to apply to the Data Protection Agency and when to apply to the scientific ethical committees is difficult, especially for young researchers. Educating researchers about these laws is therefore required in order to avoid unlawful creation and usage of biobanks.

\section{RELEVANT ACTS}

1. Redegørelse om biobanker. Forslag til retlig regulering af biobanker indenfor sundedhsområdet. Betænkning afgivet af en arbejdsgruppe nedsat af Indenrigs- og Sundhedsministeriet. Betænkning nr. 1414, Maj 2002 (In Danish).

2. The Act on Processing of Personal Data (Act no 429 of 39 May 2000).

3. The Act on Scientific Ethical Committees (Act no 402 of 28 May 2003 until 31 December 2011).

4. The Act on scientific ethical handling of health sciences research (Act no 593 of 14 June 2011 from 01 January 2012).

5. The Health Act (Act no 913 of 13 July 2010). 